\title{
Inverted L-shape line feed Quad-band Microstrip Antenna for Multiband Application
}

\author{
Manisha Waghmare \\ M. S. Bidve Engineering College, \\ Latur
}

\author{
A. K. Tamboli \\ (Associate Professor) \\ M. S. Bidve Engineering College, \\ Latur
}

\begin{abstract}
We demonstrated and presented Multi-band line feed microstrip patch antenna for wireless communication application. In proposed design, we introduced quad band antenna two rectangular slot of L-shape on patch and one rectangular shape slot on ground plane of antenna. The impedance bandwidth can be tuned by changing the ground plane geometry parameters (length and/or its width). The overall size of the antenna is $24 \mathrm{~mm} \times 22 \mathrm{~mm} \times 0.8 \mathrm{~mm}$ including finite ground feeding mechanism. The antenna operates in four bands which are
\end{abstract}

(3.3-3.6 GHz), (4.2-4.5 GHz), (6.9-7.2GHz) and (10.1$10.4 \mathrm{GHz}$ ). Stable Omni-directional radiation patterns in the desired frequency band have been obtained.

\section{Keywords}

Triple band Microstrip antenna, bandwidth enhancement, line feed technique.

\section{INTRODUCTION}

With rapid development of micro strip antenna it has been found that, Study of Microstrip antenna with symmetrical Feed Line technique, Patch Antenna experimentally increase the Return Loss up to $-33 \mathrm{~dB}$ at frequency range $2.4 \mathrm{GHz}$ to $2.5 \mathrm{GHz}$ and VSWR is less than 1.5 by using RT DUROID 5880 [1]. With further study and optimization of dual band microstrip antenna [2] it has been found that the return loss for dual band Frequency at $2.4 \mathrm{GHz}$ is $-43 \mathrm{~dB}$ and at $3 \mathrm{GHz}$ is $27 \mathrm{~dB}$ and acceptable VSWR. To get compact size and maintain performance of antenna for multiple bands that is dual band, triple band antenna etc., various shapes of antenna was integrated [3]. It was presented in [4], introducing slot into patch that is L-Shape, experimentally increase bandwidth up to $13 \%$. To enhance bandwidth further various shapes like L-shape, U-shape etc., slot was introduced and bandwidth up to $42 \%$ was increased [5,6]. In [7] and [8] the author's proposed bandwidth enhancement techniques that are by using photonic band gap structure and wideband stacked microstrip antennas respectively. By introducing stacked microstrip antenna bandwidth and gain was enhanced. While Designing of symmetrical microstrip antenna, it has been found that microstrip antenna has narrow Bandwidth $[8,9]$, Asymmetrical position of patch antenna on ground affect the performance of antenna that is to enhance bandwidth it was also found that asymmetrical position of slot on patch affects performance of antenna[9] that is asymmetrical L-shape, Ushape position of slot on patch affects the performance. In [9] designed asymmetrical slot of L-shaped on patch antenna for UWB application with acceptable return loss that is $-10 \mathrm{~dB}$ and peak gain 2.2 to $6.1 \mathrm{dBi}$ for operating bandwidth 3.01$11.30 \mathrm{GHz}$ frequencies.

In this paper we proposed L-shaped microstrip antenna using line feed with two L-shaped slots printed on dielectric substrate (pl. ref. Figure 1). The proposed antenna offers multi-bands (four) operations. Design and optimization procedure of the proposed antenna is presented in Section 2. Section 3 presents the validation of the simulated prototype and discussions on the measured results are also presented there. Finally, conclusions of this study are presented in Section 4.This antenna presents an extension to Analysis of a Miniaturized Multiresonant Wideband Slotted Microstrip Antenna With Modified Ground Plane [10].

\section{PROPOSED DESIGN}

The results of proposed quad band microstrip patch antenna verified in HFSS Simulator with optimization. The initial antenna simulation setup is shown in Figure 1(a). Actual patch shape is shown in figure 1(b), it consists of two L-shape notch on patch and one rectangular slot on ground plane. The resulting antenna structure has the following parameters; the patch shape length $\mathrm{Wp}=16 \mathrm{~mm}$, and its width $\mathrm{Lp}=12 \mathrm{~mm}$. The size of the ground plane has been found to be of $\mathrm{Lg}=22$ $\mathrm{mm}$ and $\mathrm{Wg}=24 \mathrm{~mm}$. The height of substrate is $\mathrm{h}=0.8 \mathrm{~mm}$ and dielectric constant $\mathrm{\varepsilon r}=4.4$. A line feed is attached to the microstrip and has a length 5 and width $1.8 \mathrm{~mm}$.

The key design parameters used for the optimization are dimension of L-shape (length and width of L-slot), gap between to L-shape patch and dimension of rectangular slot on ground plane. The detailed analysis of these parameters is investigated in the following paragraphs of this section. As showed in Figure 1(c), ground plane of the geometry is varied to see its effect on the performance of antenna. For this, upper and lower ground plane is changed. The ground plane is located on the reverse side of the substrate in the shape of a rectangle, covering the entire back. Return loss characteristics of this study are presented in Figure 2.

From Figure 1(c) it may be noted that ground plane dimensions are finalized to get quad bands. Further we changed width of L-shape (Wt), length of L-shape (d) and gap. Figures (2), (3) and (4) show return loss characteristics plots of this study. From these figures it may be noted that the quad bands can be obtained for $\mathrm{Wg}=24 \mathrm{~mm}, \mathrm{Lg}=22 \mathrm{~mm}$, and $\mathrm{Lg} 2=12 \mathrm{~mm}$. The finalized dimensions obtained from these parametric studies are presented in Table 1.

\begin{tabular}{|c|c|c|c|c|c|c|c|c|c|}
\hline Parameter & $L_{p}$ & $W_{p}$ & $d$ & $W t$ & $W_{s}$ & $\mathrm{~L}_{\mathrm{t}}$ & $W_{g}$ & $L_{g}$ & $\mathrm{D}_{\mathrm{p}}$ \\
\hline Unit(mm) & 16 & 12 & 7 & 1.2 & 3 & 5 & 24 & 22 & 8 \\
\hline
\end{tabular}

To study the effect of L-shape dimensions on the antenna performance, its dimension values i.e., $\mathrm{d}, \mathrm{Wt}$ and $\mathrm{Dp}$ are varied. Initially, length of L-shape on patch varied from $6 \mathrm{~mm}$ to $8.5 \mathrm{~mm}$ in steps of $0.5 \mathrm{~mm}$ keeping dimension of ground plane constant and return loss is presented in figure 2 . The effects of variation of this study for different values of Wt and Dp in steps of $0.1 \mathrm{~mm}$ and $1 \mathrm{~mm}$ respectively are presented in 
Figure 3 and Figure 4, it may be noted that the quad bands with return loss less than $-15 \mathrm{~dB}$ are $(3.3-3.6 \mathrm{GHz}),(4.2-$ $4.5 \mathrm{GHz}),(6.9-7.2 \mathrm{GHz})$, and (10.1-10.4GHz).

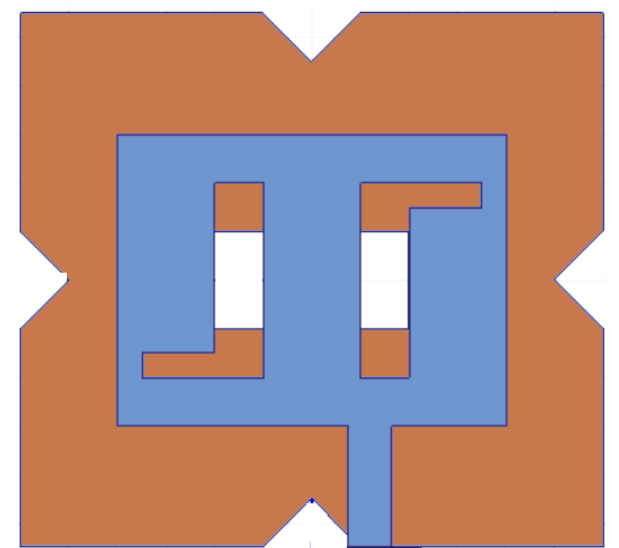

Figure 1(a). Proposed antenna simulation setup

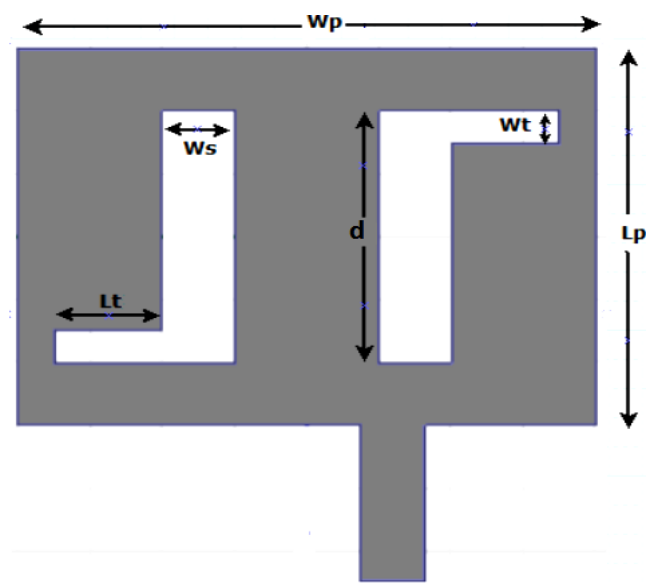

Figure 1(b). Proposed antenna design (Patch)

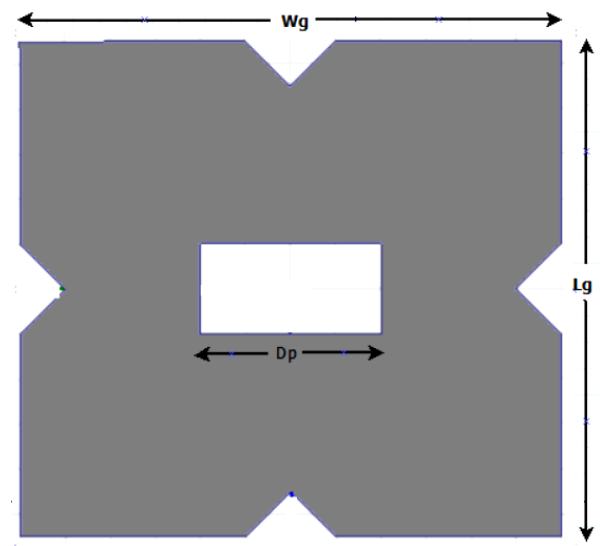

Figure 1(c). Proposed antenna design (Ground)

From figure 2 and figure 3 , it is observed that, we get minimum return loss that is $-25 \mathrm{~dB},-15 \mathrm{~dB},-20 \mathrm{~dB}$ and $-45 \mathrm{~dB}$ at $3.3 \mathrm{GHz}, 4.1 \mathrm{GHz}, 7.00 \mathrm{GHz}$ and $10.2 \mathrm{GHz}$ respectively.



Fig 2: Return loss of antenna for variation in L-slot on Patch ( variation in "d")

Results of the variation of the size of the ground plane, as Figure 4 implies that the quad band response increases for ground plane reduction by introducing slot into it.

However, quad-band responses are obtained with increased or decreased higher resonating bands. The effect of the width of ground has been demonstrated in Figure 3, and Figure 4.

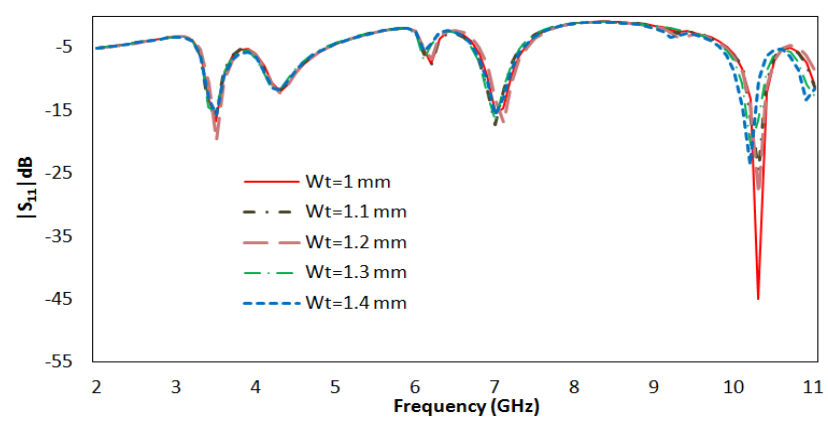

Fig 3: Return loss of antenna for variation in L-slot on Patch (Variation in "W")

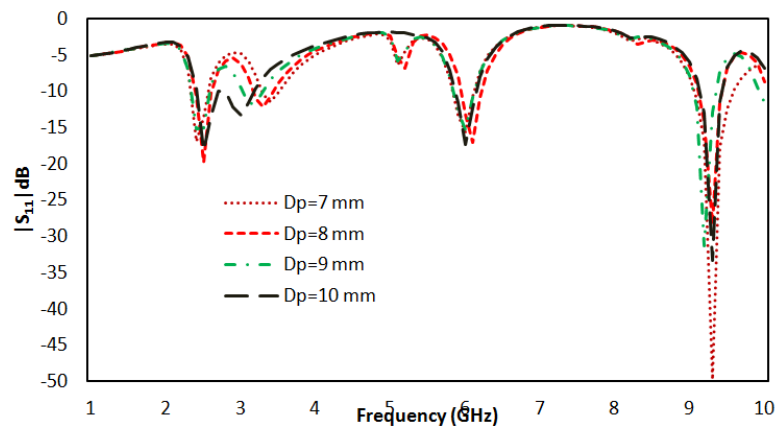

Fig 4: Return loss of antenna for variation of slot on ground plane

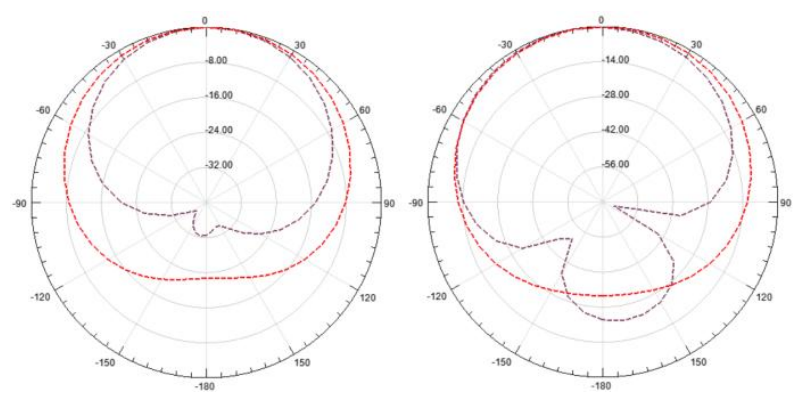

Fig 5: E- and H-plane patterns at $3.3 \mathrm{GHz}$ 




Fig 6: E- and H-plane patterns at $4.3 \mathrm{GHz}$

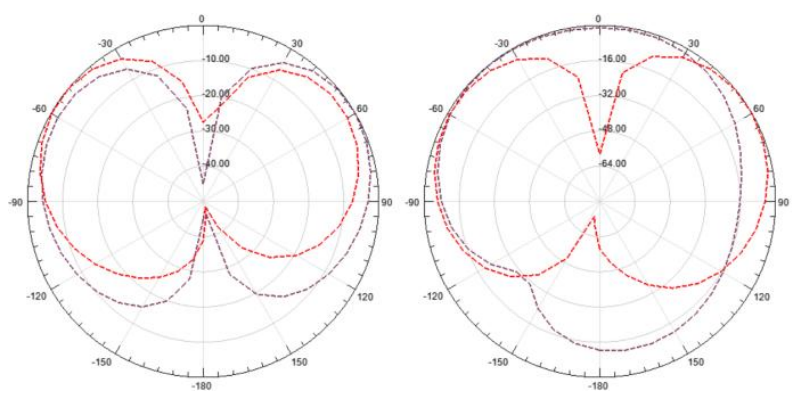

Fig 7: E- and H-plane patterns at 7.0 GHz



Fig 8: E- and H-plane patterns at $10.0 \mathrm{GHz}$

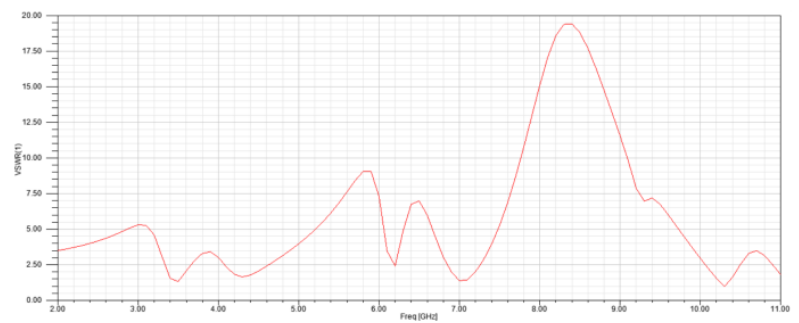

Fig. 7 VSWR

Figure (5)-(8) depicts the radiation pattern for quad band that is at $3.3 \mathrm{GHz}, 4.3 \mathrm{GHz}, 7.00 \mathrm{GHz}$ and $10.0 \mathrm{GHz}$ frequency since return loss at this frequency is $-25 \mathrm{~dB},-15 \mathrm{~dB},-20 \mathrm{~dB}$ and $45 \mathrm{~dB}$ respectively. Figure(7) represents VSWR for all band, VSWR is less than 2 for all band that is good matching between feed line patch.

\section{CONCLUSION}

The design optimization of a two slot patch antenna has been presented and discussed. It has been shown that, with correct selection of slot dimensions on patch and shape of ground plane, a quad band frequency response can be achieved. With this antenna, we get quad band that is $(3.3-3.6 \mathrm{GHz}),(4.2-$ $4.5 \mathrm{GHz}),(6.9-7.2 \mathrm{GHz})$, and $(10.1-10.4 \mathrm{GHz})$. The antenna has been modeled and its performance has been analyzed using a HFSS simulator. The proposed antenna has been found to possess a miniaturized size and acceptable return loss at respective band with perfect matching. The simulated results of HFSS at $3.3 \mathrm{GHz}$ is Return loss $=-25 \mathrm{~dB}$, at $4.3 \mathrm{GHz}$ Return loss $=-15 \mathrm{~dB}$, at $7.00 \mathrm{GHz}$ Return loss $=-20 \mathrm{~dB}$ and at $10.1 \mathrm{GHz}$ Return loss $=-45 \mathrm{~dB}$. VSWR at $3.3 \mathrm{GHz}$ is 1.3 .

\section{REFERENCES}

[1] Ahmed H. Reja "Study of Micro Strip Feed Line Patch Antenna", Antennas and Propagation International Symposium, vol. 27, pp. 340-342 December 2008.

[2] Sahntanu Kumar Behera and Y. Choukiker, "Design and Optimization of Dual Band Micro Strip Antenna Using Practicle Swarm Optimization Technique," Springer Science Business Media, LLC, pp. 1346-1354, 2010

[3] M. A. S. Alkanhal, "Compact composite triple band antenna", Progress In Electromagnetics Research, PIER 93, 221-236, 2009

[4] A. A. Deshmukh and G. Kumar, "Compact broadband gap-coupled shorted L-shaped microstrip antennas," IEEE Antennas and Propagation International Symposium, vol 1, (Baltimore, Maryland), pp. 106-109, IEEE, July 2001.

[5] Z. M.Chen and Y. W. M. Chial, "Broadband probe-fed L-shaped plate antenna," Microwave and Optical Technology Letters, vol. 26, pp. 204-206, 1985.

[6] K. F. Lee, K. M. Luk, K. F. Tong, Y. L. Yung, and T. Huynh, "Experimental study of the rectangular patch with a U-shaped slot," IEEE Antennas and Propagation International Symposium, vol.1, (Baltimore, Maryland), pp. 10-13, IEEE, July 1996.

[7] S. C. Gao, L. W. Li, M. S. Leong, and T. S. Yeo, "Design and analysis of a novel wideband microstrip antenna," IEEE Antennas and Propagation International Symposium,vol.1, (Boston, Massachusetts), pp. 90-93, IEEE, July 2001.

[8] M. Khodier and C. Christodoulou, "A technique to further increase the bandwidth Of stacked microstrip antennas," IEEE Antennas and Propagation International Symposium, vol. 3, pp. 1394-1397, IEEE, July 2000.

[9] K. Song, Y.-Z. Yin, S.-T. Fan, and B. Chen," compact open ended L-shaped slot antenna with asymmetrical rectangle patch for UWB application", Progress In Electromagnetics Research C, Vol. 19, 235-243, 2011

[10] Sudipta Das, Parimal Chowdhury, Arindam Biswas, Partha Pratim Sarkar, and Santosh Kumar Chowdhury "Analysis of a Miniaturized Multi-resonant Wideband Slotted Microstrip Antenna With Modified Ground Plane," IEEE antennas and wireless propogation letter vol. 14, 2015

[11] V.V.Reddy, N. V. S. N. Sarma, "Triband Circularly Polarized Koch Fractal Boundary Microstrip Antenna", IEEE antennas and wireless propagation letters, vol. 13, 2014

[12] T.-H. Chang and J.-F. Kiang, "Compact multi-band Hshaped slot antenna,"IEEE Trans. Antennas Propag., vol. 61, no. 8, pp. 4345-4349,

[13] K. Song, Y.-Z. Yin, S.-T. Fan, and B. Chen, "compact open-ended 1-shaped slot antenna with asymmetrical rectangular patch for UWB applications", Progress In Electromagnetics Research C, Vol. 19, 235-243, 2011. 